Agr. Biol. Chem., 40 (1), 33 40, 1976

\title{
On the Interaction of Melanoidin with Metallic Ions
}

\author{
Toshiharu Gomyo and Masayo Horikoshr \\ Laboratory of Nutritional Science of Food, Kagawa Nutrition College, \\ Toshima-ku, Tokyo \\ Received May 21, 1975
}

\begin{abstract}
Melanoidin, which is obtained from the browning solution prepared from glycine-Dglucose system by acid precipitation, displays a noticeable character attributable to an amphoteric polyvalent electrolyte with the isoelectric point at $\mathrm{pH} 2.5$. The number of proton released during titration from the isoelectric point to $\mathrm{pH} 11.0$ is $\mathrm{ca} .500$ per one molecule of melanoidin. Thus, melanoidin shows a remarkable coagulation in the presence of various metallic ions though affected by metal concentration, $\mathrm{pH}$ and the presence of other chelating agent such as EDTA. The behavior of melanoidin towards metallic ions is in common with anionic hydrophillic colloids. The metal binding ability of melanoidin was confirmed on the basis of difference spectra, titration curves and dialysis equilibria. The stability constants and the number of binding sites were approximately calculated from the results of dialysis equilibria in respect to $\mathrm{Fe}^{3+}$ and $\mathrm{Cu}^{2+}$. Melanoidin was evaluated as a powerful metal scavenger in an attempt to elucidate its antioxidative effect.
\end{abstract}

Not little efforts have been expended on attempts to characterize melanoidin, brown polymeric compounds resulting from the amino-carbonyl reaction. ${ }^{1}$ However, poor informations are available in respect to the molecular structure of this colored product because of disorder of bonding as well as polydispersity of molecular weight. On the basis of structural features, melanoidin is considered to belong to a series of complicated and ambiguous polymers including humic substance, lignin, melanin, caramel, coal tar and so on.

In recent works, melanoidin has been taken notice of concerning some interesting properties such as antioxidative ${ }^{2)}$ and antimicrobial activities ${ }^{3,4)}$ from the viewpoint of preservation of food stuffs.

It is reasonable that melanoidin is regarded as a polyvalent electrolyte according to its behavior in various solvents. This ionic property suggests that melanoidin plays a role in autoxidation of lipids in food as a metal scavenger. To say the least of it, an acid synergist represents an important aspect of antioxidative effect of melanoidin.

The purpose of this paper is to provide informations on the interaction of metallic ions such as $\mathrm{Fe}^{3+}, \mathrm{Al}^{3+}, \mathrm{Cu}^{2+}, \mathrm{Zn}^{2+}, \mathrm{Co}^{2+}$ and $\mathrm{Mn}^{2+}$ with melanoidin produced from the system composed of glycine and D-glucose, referring to elucidation of its ionic properties.

\section{EXPERIMENTAL}

Preparation of melanoidin. The aqueous solution containing $2 \mathrm{M}$ of glycine, $2 \mathrm{M}$ of D-glucose and $0.2 \mathrm{M}$ $\mathrm{NaHCO}_{3}$ was heated at $95^{\circ} \mathrm{C}$ for $36 \mathrm{hr}$. The resulting brown solution was diluted twice, and adjusted to pH 2.5 with $\mathrm{HCl}$. After standing overnight, the precipitate was separated by centrifuging at $3000 \mathrm{rpm}$ for $20 \mathrm{~min}$ and suspended in ten parts of water. The suspension was put into solution by adjusting $\mathrm{pH}$ to 11.0 with $\mathrm{NaOH}$. This limpid solution was adjusted to pH 2.5 with $\mathrm{HCl}$, and the suspension was centrifuged at $14,000 \mathrm{rpm}$ for $20 \mathrm{~min}$. Again, the precipitate was dissolved in the above manner. This treatment was repeated twelve times. Finally, the precipitate obtained was lyophilized into a brownish powder, and stored in vacuo in the cold room. The yield against the weight of the starting material (glycine plus Dglucose) was $17.1 \%$. The color in terms of O.D.470 was $67.6 \%$. Found: $\mathrm{C}, 53.0 ; \mathrm{H}, 5.1 ; \mathrm{O}, 35.6 ; \mathrm{N}, 6.3 \%$. This substance was practically nondiffusable through a cellophane film, indicating the absence of lower molecule fraction of colored matter, and was employed as "melanoidin" in this study. 
Examination of the distribution of molecular weight of melanoidin. A gel permeation chromatography was carried out using Bio-Gel P-300 charged in a glass column $(3 \times 85 \mathrm{~cm})$ filled with glass beads (diameter; $7 \sim 9 \mathrm{~mm}$ ) which were expected to facilitate the elution procedure. ${ }^{5}$ ) The net volume of gel was $220 \mathrm{ml}$. The Gel was previously equilibrated with $0.1 \mathrm{M}$ acetate buffer ( $\mathrm{pH} \mathrm{6.0)}$ as a developing solvent. The flow rate was kept at about $0.4 \mathrm{ml}$ per $\mathrm{min}$. The following compounds were used as markers: Blue Dextran 2000 (Pharmacia Fine Chemicals), ovalbumin and fiavin mononucleotide Na salt (Wako Pure Chemical Industries, Ltd.).

Titration curves. Twenty-five $\mathrm{mg}$ of melanoidin was suspended in $40.0 \mathrm{ml}$ of $0.1 \mathrm{M} \mathrm{KCl} \mathrm{CO}$-free deionized water. This was brought into solution by adding $1.00 \mathrm{ml}$ of $1.00 \mathrm{~N} \mathrm{KOH}$ with stirring under $\mathrm{N}_{2}$ gas flow. The solution was then added $1.50 \mathrm{ml}$ of $1.00 \mathrm{~N} \mathrm{HCl}$ to be adjusted to pH $2.5 \sim 3.0$. After added an aliquot of $0.01 \mathrm{M}$ of metallic ion solution, titrations were performed against the standard solution of $0.02 \mathrm{~N} \mathrm{KOH}$ in $0.1 \mathrm{M} \mathrm{KCl}$ with continuous stirring in $\mathrm{N}_{2}$ atmosphere and at the room temperature $\left(20 \sim 23^{\circ} \mathrm{C}\right)$. Curves were recorded using a Horiba autotitrator $\mathrm{T}-1$. In order to confirm the amount of free $\mathrm{HCl}$ present in the above system, a blank solution lacking in both melanoidin and metallic ion was titrated in the same manner. All solutions used in the above study were prepared in $\mathrm{CO}_{2}$-free deionized water.

Estimation of coagulation or precipitation of melanoidin. Turbid solutions resulting from various treatments were centrifuged at $14,000 \mathrm{rpm}$ for $20 \mathrm{~min}$, and O.D. 470 of the supernatant was determined with a spectrophotometer Hitachi 181 .

$U V$ spectra of melanoidin. The spectroscopy was carried out with a spectrophotometer Hitachi 124 connected with a Hitachi Recorder QPD 34.

Paper electrophoresis. The behavior of melanoidin in the electric field was followed on a filter paper Toyo Roshi No. 2 (length $37 \mathrm{~cm} /$ width $18 \mathrm{~cm}$ ) through which an electric current was sent at $15 \mathrm{~mA}$ at room temperature for two hours. The fixed current was supplied from a stabilized D.C. supply CV II-model N of Kyowa Vacuum Industry Co, Ltd.

Dialysis equilibrium. Five hundreds $\mathrm{mg}$ of melanoidin was dissolved in $50 \mathrm{ml}$ of $0.1 \mathrm{M} \mathrm{KCl}$ at $\mathrm{pH} 12$, and dialyzed against $1000 \mathrm{ml}$ of $0.1 \mathrm{M} \mathrm{KCl}$ at $\mathrm{pH} 3.8$ for $30 \mathrm{hr}$. The content in the cellophane tube was made up to $100 \mathrm{ml}$ with $0.1 \mathrm{M} \mathrm{KCl}$ at $\mathrm{pH} 3.8$, and diluted twice with $2 \times 10^{-4} \mathrm{M} \mathrm{FeCl}_{3}$ in $0.1 \mathrm{M} \mathrm{KCl}$ at pH 3.8. An aliquot of this solution was diluted 1 to 1 and 1 to 5 with $10^{-4} \mathrm{M} \mathrm{FeCl}_{3}$ in $0.1 \mathrm{M} \mathrm{KCl}$ at pH 3.8. Thus, $50 \mathrm{ml}$ of each solution in a cellophane tube was dialyzed against $200 \mathrm{ml}$ of $10^{-4} \mathrm{M} \mathrm{FeCl}_{3}$ in $0.1 \mathrm{M} \mathrm{KCl}$ at pH 3.8 for five days at $20^{\circ} \mathrm{C}$. Finally, the decrement of in the outer solution was measured. The above manner was followed in the case of $\mathrm{Cu}^{2+}$, also.

Measurements of $\mathrm{Fe}^{3+}$ and $\mathrm{Cu}^{2+}$. Ferric ion was measured by bathophenanthroline method after reduced by hydroquinone. Cupric ion was measured by Na-diethyldithiocarbamate method.

\section{RESULTS}

Influences of pH, ionic strength and solvents on the solubility of melanoidin

The solubility of melanoidin is specifically dependent on $\mathrm{pH}$ as seen in Fig. 1. Melanoidin obtained from the system of glycine and D-glucose had an apparent minimum point of solubility at about $\mathrm{pH} 2.5$, while a gradual decrease in solubility occurred below $\mathrm{pH} 1$, as well. Such $\mathrm{pH}$ profile of solubility suggests a

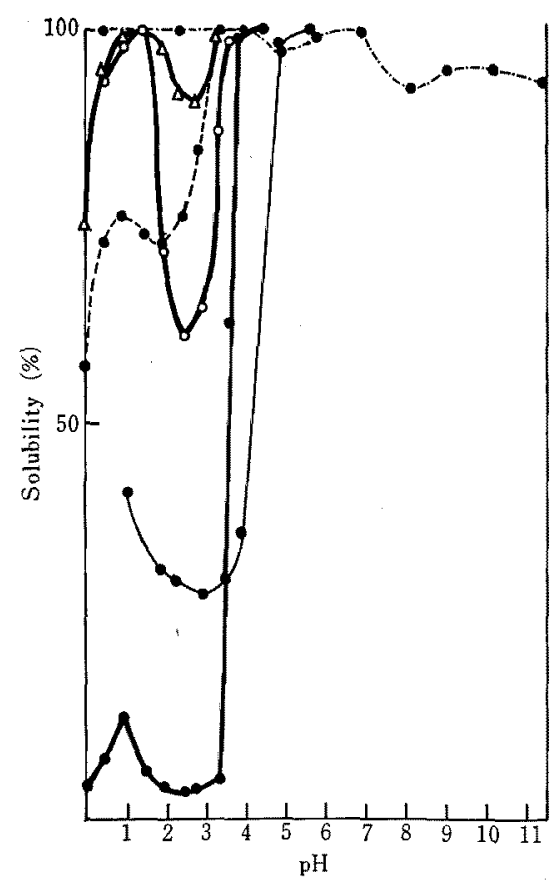

FIG. 1. pH Profiles of Solubility of Melanoidin.

Aliquots of browning reaction solution were adjusted to various $\mathrm{pH}$ with $\mathrm{HCl}$ or $\mathrm{NaOH}$, and centrifuged to obtain the supernatants whose absorbance at $470 \mathrm{~nm}$ was measured. Reaction mixture: amino acid $1 \mathrm{M}$, D-glucose $1 \mathrm{M}, \mathrm{NaHCO}_{3} 0.1 \mathrm{M}$. Heated at $95^{\circ} \mathrm{C}$.

$\longrightarrow$, glycine; - , L-valine; - , L-glutamic acid; ...-.--, l-arginine; $\triangle, 24 \mathrm{hr} ; 0,36 \mathrm{hr} ; 0,90 \mathrm{hr}$. 


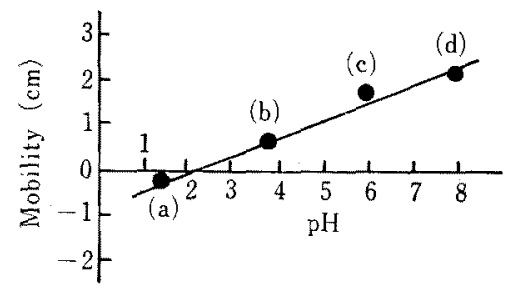

Fig. 2. Effect of $\mathrm{pH}$ on Electrophoresis of Acidprecipitate Melanoidin.

Paper electrophoresis was done at room temp. for $2 \mathrm{hr}$. Using a filter paper Toyo Roshi No. 2 (length $37 \mathrm{~cm}$, width $18 \mathrm{~cm}$ ) under $15 \mathrm{~mA}$. Electrode solution was sat. $\mathrm{KCl}$. Following buffer solutions were used; (a) $\mathrm{M} / 20 \mathrm{KCl}-\mathrm{HCl}, \mathrm{pH} 1.4$, (b) $\mathrm{M} / 20 \mathrm{HCl}-\mathrm{KH}$ phthalate, $\mathrm{pH} 3.8$, (c) $\mathrm{m} / 20 \mathrm{NaOH}-\mathrm{KH}$ phthalate, $\mathrm{pH} 6.0$, (d) $\mathrm{M} / 20 \mathrm{NaOH}-\mathrm{KH}_{2} \mathrm{PO}_{4}, \mathrm{pH} 8.0$.

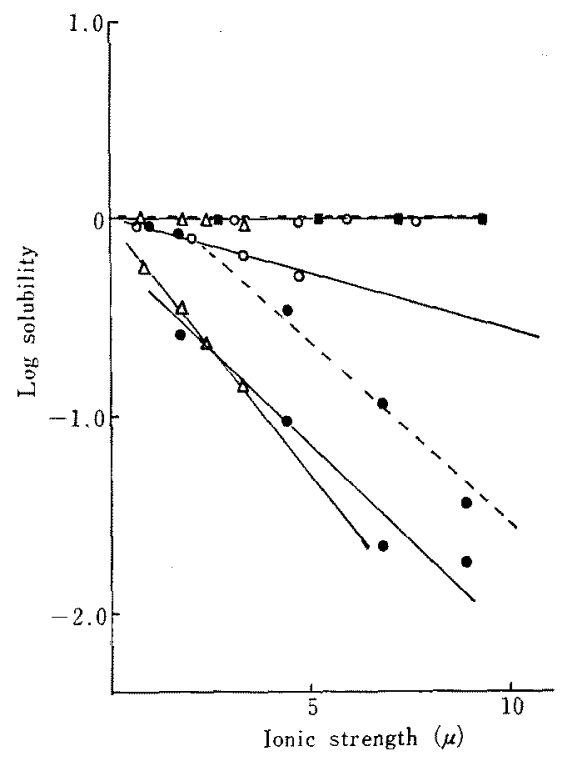

Fig. 3. Effect of Ionic Strength on Solubility of Melanoidin.

Melanoidin $0.08 \%$. -, $\mathrm{pH} 3.5 ;-\ldots, \mathrm{pH} 6.5$; -, $\left(\mathrm{NH}_{4}\right)_{2} \mathrm{SO}_{4} ; \triangle, \mathrm{Na}_{2} \mathrm{SO}_{4} ; \mathrm{O}, \mathrm{NaCl} ; \mathbf{m}, \mathrm{MgCl}_{2}$.

view on which melanoidin is distinguished by amphoteric electrolytes. Probably, the $\mathrm{pH}$ giving the minimum solubility inflects the isoelectric point of melanoidin though in terms of average. In fact, melanoidin didn't move around $\mathrm{pH} 2.5$ in the electric field as shown in Fig. 2. This isoelectric point shifted in accordance with the kinds of amino acid as a starting material for preparation of melanoidin. In comparison with $\mathrm{pH} 2.5$ for glycine, the

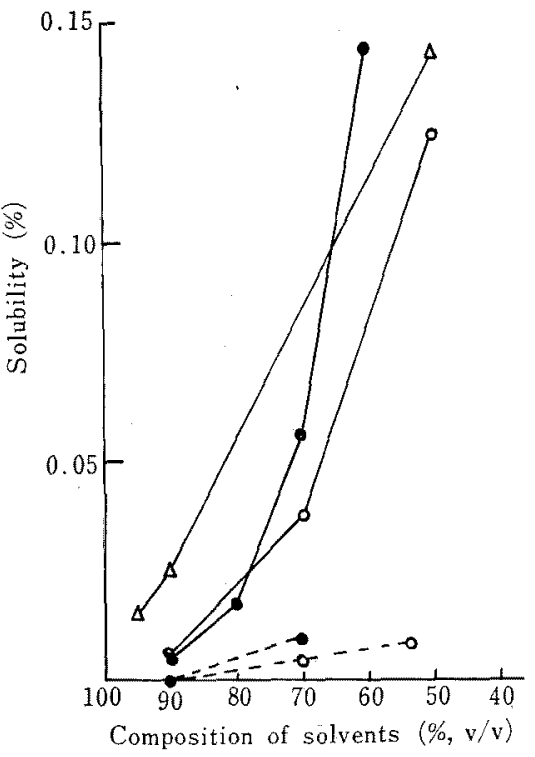

FIG. 4. Effect of Organic Solvents on Solubility of Melanoidin.

-_, unfractionated melanoidin; - - - acid-precipitated melanoidin; $\bullet-\bullet$, ethanol; $\triangle-\triangle$, methanol; $\mathrm{O}-\mathrm{O}$, acetone.

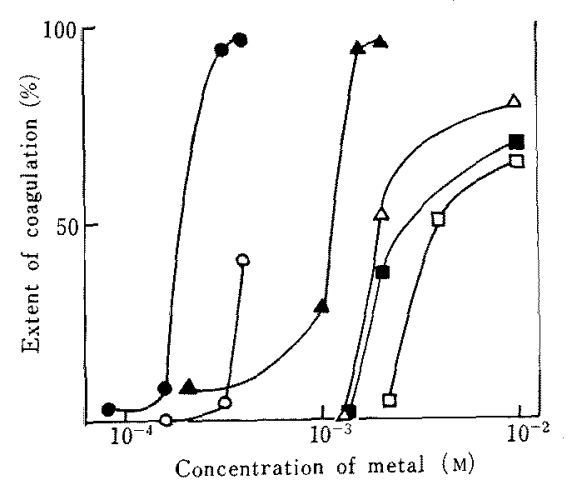

Fig. 5. Effect of Concentration of Metallic Ions on Coagulation of Melanoidin.

Melanoidin $0.02 \%$, pH 3.8 . The suspension caused by addition of metals was centrifuged at $14,000 \mathrm{rpm}$ for $5 \mathrm{~min}$ after standing overnight, and the supernatant was measured colorimetrically at $470 \mathrm{~nm}$. The extent of coagulation is shown as a decrement of the absorbance.

$\bullet-\bullet, \mathrm{AlCl}_{3} ; \mathrm{O}_{-} \mathrm{O}, \mathrm{FeCl}_{3} ; \Delta-\Delta, \mathrm{CuSO}_{4} ; \Delta-\Delta$, $\mathrm{ZnSO}_{4} ;--\mathbf{C o C l} ; \square-\square, \mathrm{MnCl}_{2}$.

isoelectric point is 2.0 for L-glutamic acid, 3.0 for L-valine and 8.0 for L-arginine, respectively. This order appears to relate to the acidity or basicity of side chains of these amino acids. 


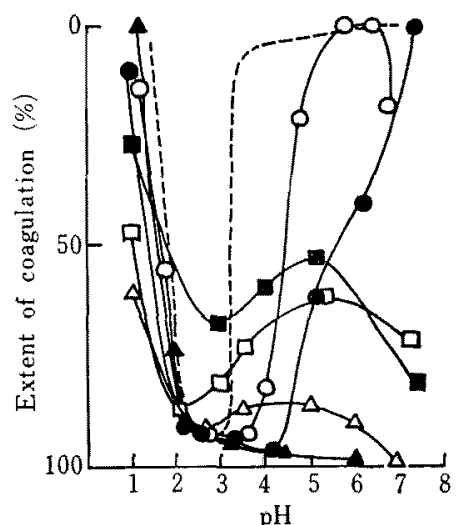

Frg. 6. pH Profiles of Coagulation of Melanoidin in the Presence of Metallic Ions.

Melanoidin $0.02 \sim 0.05 \%$.

- $-\mathrm{AlCl}_{3} 3 \times 10^{-4} \mathrm{M} ; \mathrm{O}-\mathrm{O}, \mathrm{FeCl}_{3} 3 \times 10^{-4} \mathrm{M}$;

$\triangle-\Delta, \mathrm{CuSO}_{4} 2 \times 10^{-3} \mathrm{M} ; \triangle-\triangle, \mathrm{ZnSO}_{4} 4 \times 10^{-2} \mathrm{M}$;

- $-\mathrm{CoCl}_{2} 4 \times 10^{-2} \mathrm{M} ; \square-\square, \mathrm{MnCl}_{2} 4 \times 10^{-2} \mathrm{M}$; - - , control without metal.

It can be given as a conclusion that side groups of amino acids remain in melanoidin molecule and affect its electrolytic character. On the other hand, it is observed that the valley of solubility curves inclines to become broader and deeper on the acidic side beyond the minimum point with elongation of heating time for preparation of melanoidin. This indicates that basic groups in melanoidin molecules disappear as polymerization proceeds to a higher extent.

Melanoidin is salted out by addition of various kinds of salts, as shown in Fig. 3. On the other hand, solutility of melanoidin decreases with lowering of polarity of the medium by addition of hydrophillic organic solvents such as methanol, ethanol and acetone (Fig. 4). These facts, in general, are characteristic of hydrophillic colloids. Therefore, it is anticipated that heavy metallic ions interact with melanoidin as a polymer of polyvalent electrolyte.

Effect of concentration of metallic ions on coagulation of melanoidin

Metallic ions cause remarkable coagulation of melanoidin. The extent of coagulation, however, is distinctly dependent on concentration of metallic ions as seen in Fig. 5. And, the critical concentration of metallic ions required to coagulate melanoidin is affected by species of metals, especially by valence of ions. Trivalent ions such as $\mathrm{Al}^{3+}$ and $\mathrm{Fe}^{3+}$ are more effective than divalent ones such as $\mathrm{Cu}^{2+}$, $\mathrm{Zn}^{2+}, \mathrm{Co}^{2+}$ and $\mathrm{Mn}^{2+}$. Cations of the same valence are not always identical each other in their effects. Evidently, melanoidin in the presence of metallic ions exhibits the behavior generally attributed to negatively charged colloids. $^{6,7)}$

\section{Effect of pH on coagulation of melanoidin by metallic ions}

The $\mathrm{pH}$ profile of coagulation considerably varied with the kind of metallic ions as shown in Fig. 6. Such pH dependences can be accounted on the states of electric charge of both melanoidin and metals. While no coagulation occurred below pH 2.0 where melanoidin positively charged, a remarkable interaction between melanoidin and metals was observed over that $\mathrm{pH}$ though it is partly due to isoelectric precipitation. However, there are decreases in coagulation toward the higher region of $\mathrm{pH}$ where metal hydroxide is formed. It is considered that metal hydroxide is unavailable for metal-melanoidin complex formation. Over $\mathrm{pH} \mathrm{7,} \mathrm{however,} \mathrm{there} \mathrm{appears}$ to be effective coagulation. This phenomenon is ascribed to melanoidin being involved in precipitate of metal hydroxide. The inflection points on titration curves of $\mathrm{Cu}^{2+}, \mathrm{Al}^{3+}$ and $\mathrm{Fe}^{3+}$ are $\mathrm{pH}$ 6.8, 5.5, and 3.7, respectively. This order is in good agreement with that of the $\mathrm{pH}$ range to allow melanoidin to coagulate in the presence of those metallic ions. This tendency must be true of the case of divalent cations such as $\mathrm{Zn}^{2+}, \mathrm{Co}^{2+}$ and $\mathrm{Mn}^{2+}$ as well though the precise $\mathrm{pH}$ profile of coagulation is difficult to draw over the wide range of $\mathrm{pH}$ on account of the interference by the formation of metal hydroxide. For, the concentration of divalent cations required to coagulate melanoidin is much higher than that of trivalent cations.

Peptisation of coagulate produced from mela- 
noidin and metallic ions by addition of EDTA

Suspension containing coagulate produced from melanoidin-metallic ion system can be brought into solution by addition of such a chelating agent as ethylenediaminetetraacetic acid (EDTA). This is due to the fact that metals are deprived of melanoidin by EDTA. Such peptisation, however, is actualized at a certain concentration of EDTA as seen in Fig. 7. Evidently, EDTA plays a competitive role with melanoidin against metallic ions. This also implies that coagulating of melanoidin is based on the reversible binding of metallic ions. As above mentioned, $\mathrm{Fe}^{3+}$ is more effective in coagulating melanoidin than $\mathrm{Cu}^{2+}$, while peptisation is easier in the former than in the latter. The reason is that $\mathrm{Fe}^{3+}$ is stronger in the affinity with EDTA than $\mathrm{Cu}^{2+}$.

Effect of metallic ions on UV spectra of melanoidin

Figures 8 and 9 indicate significant effects of $\mathrm{Fe}^{3+}$ and $\mathrm{Cu}^{2+}$ on UV spectra of melanoidin, respectively. The difference between (a) and $\left(a^{\prime}\right)$ implies the change of melanoidin itself in the presence of metallic ions. On the other hand, that between (b) and $\left(b^{\prime}\right)$ shows the

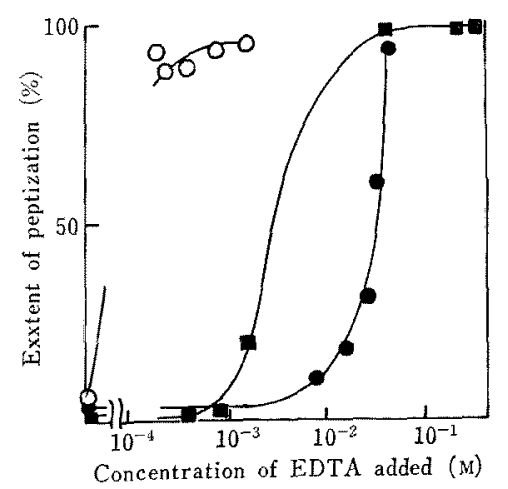

FIG. 7. Peptisation of Metal-caused Coagulate of Melanoidin by Addition of EDTA (Disodium Ethylenediaminetetraacetate).

Melanoidin $0.4 \mathrm{~g} /$ liter, $\mathrm{pH} 4.0, \mathrm{u}=0.1$. The suspension of melanoidin caused by addition of metals, $\mathrm{AlCl}_{3} 4 \times 10^{-4} \mathrm{M}, \mathrm{FeCl}_{3} 4 \times 10^{-3} \mathrm{M}, \mathrm{CuSO}_{4} 4 \times 10^{-3} \mathrm{M}$, was added EDTA at various concentrations, and centrifuged to estimate the absorbance at $470 \mathrm{~nm}$ of the supernatant. Extent of peptisation is shown as the increment of the absorbance.

$\mathrm{O}-\mathrm{O}, \mathrm{AlCl}_{3}$;

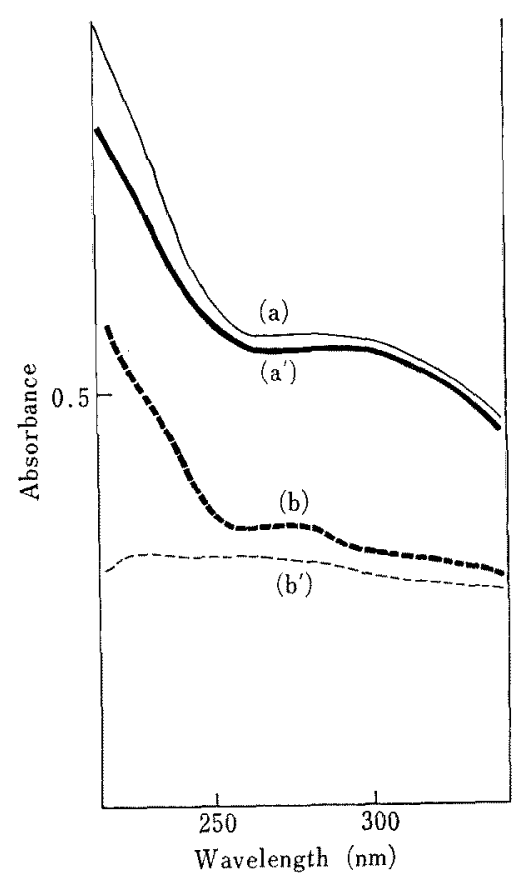

FIG. 8. Effect of $\mathrm{Fe}^{3+}$ on UV Spectra of Melanoidin.

Melanoidin $0.006 \%, \mathrm{FeCl}_{3} 5 \times 10^{-5} \mathrm{M}$, pH 3.8 .

- , melanoidin against water as reference; melanoidin $+\mathrm{Fe}^{3+}$ against $\mathrm{Fe}^{3+}$ as reference; --.---, $\mathrm{Fe}^{3+}$ against water as reference; -...-., melanoidin + $\mathrm{Fe}^{3+}$ against melanoidin as reference.

influence of melanoidin on the spectra of metallic ions. These facts present evidences that the interaction between melanoidin and metallic ions brought about some structural changes resulting from a complex or a chelate formation. However, no spectral changes over the range of visible light are observed.

\section{Effect of metallic ions on titration curves of melanoidin}

Interactions between melanoidin and metallic ions are evidently confirmed on titration curves with dilute base as shown in Figs. 10 and 11. First, the amount of base consumed in the system of melanoidin +metal is much less than the calculated sum of each titration value of metallic ions and melanoidin. The higher concentration of metallic ions added, the more decrement of titration value was observed. Such decreases in the number of protons released were reasonably attributed to 


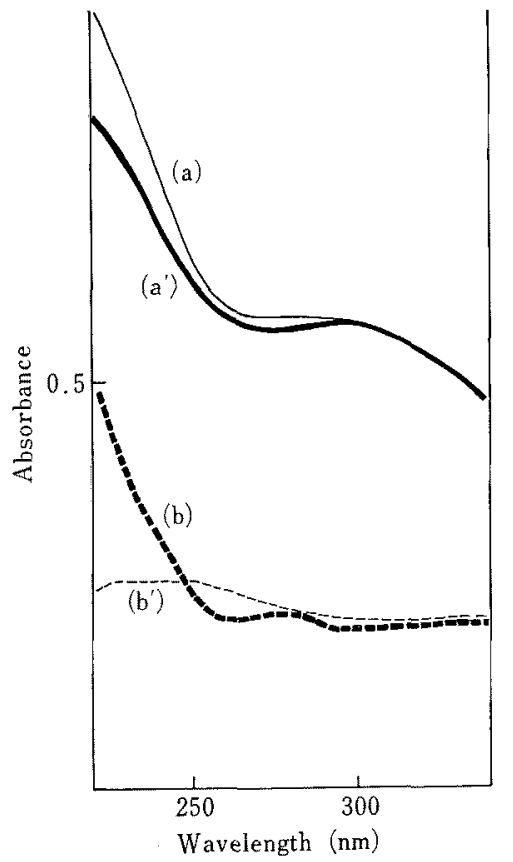

FIG. 9. Effect of $\mathrm{Cu}^{2+}$ on UV Spectra of Melanoidin.

Melanoidin $0.006 \%, \mathrm{CuSO}_{4} 10^{-4} \mathrm{M}, \mathrm{pH} 3.8$.

- , melanoidin against water as reference; melanoidin $+\mathrm{Cu}^{2+}$ against $\mathrm{Cu}^{2+}$ as reference; -..-.-, $\mathrm{Cu}^{2+}$ against water as reference; -----, melanoidin + $\mathrm{Cu}^{2+}$ against melanoidin as reference.

changes of melanoidin molecule by metalbinding, which puts the dissociative groups out of the medium. On the other hand, it should be noted that inflections in the titration curves characteristic of the formation of metal hydroxide are nearly absent when melanoidin is added to the metallic ion solutions. This indicates that the added metals also form complexes with melanoidin.

Ferric ion is more effective in affecting titration curves of melanoidin than cupric ion as well as in causing coagulation. The titration curves indicate that melanoidin molecule possesses a considerable number of dissociative groups which are possibly dispersive in titration constants. From pH 2.5 (isoelectric point) to $\mathrm{pH} 10.0$, for example, about 500 moles of proton are released from $10^{5} \mathrm{~g}$ of melanoidin, which is roughly taken for the order of molecular weight of melanoidin as based on the gel permeation chromatography

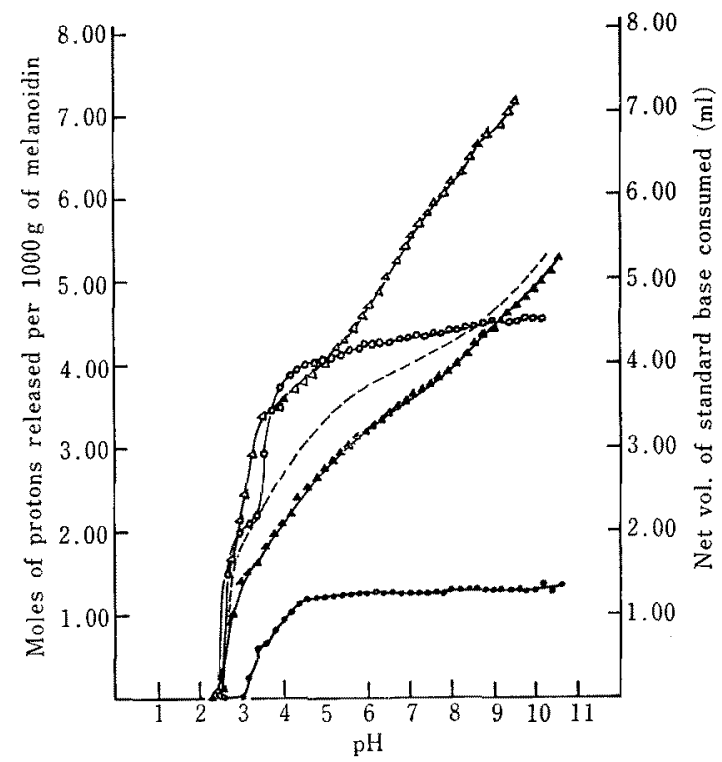

FIG. 10. Effect of $\mathrm{Fe}^{3+}$ on Titration Curves for Melanoidin.

The starting volume was $50.0 \mathrm{ml}$ containing $20.0 \mathrm{mg}$ of melanoidin. $u=0.1$. The run was done against $0.02 \mathrm{~N} \mathrm{KOH}(\mathrm{u}=0.1)$ as a standard base at room temperature $20 \sim 23^{\circ} \mathrm{C}$. The reaction vessel was free from $\mathrm{CO}_{2}$ by bubbling $\mathrm{N}_{2}$ gas.

,---- melanoidin; $-\mathrm{Fe}^{3+} 10 \mu$ moles; $\mathrm{O}-\mathrm{O}$, $\mathrm{Fe}^{3+} 30 \mu$ moles; $\mathbf{A}-\mathbf{A}$, melanoidin $+\mathrm{Fe}^{3+} 10 \mu$ moles; $\triangle-\triangle$, melanoidin $+\mathrm{Fe}^{3+} 30 \mu$ moles.

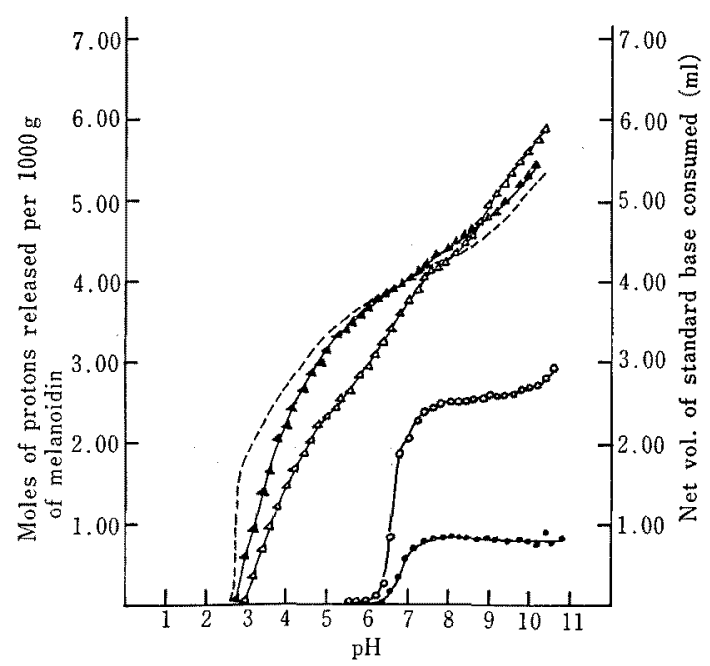

Fig. 11. Effect of $\mathrm{Cu}^{2+}$ on Titration Curves for Melanoidin.

The run was done in the same way as shown in Fig. 10. ----, melanoidin; $-1 \mathrm{Cu}^{2+} 10 \mu$ moles; $\mathrm{O}-\mathrm{O}$, $\mathrm{Cu}^{2+} 30 \mu$ moles; $\mathbf{\Lambda}-\mathbf{\Lambda}$, melanoidin $+\mathrm{Cu}^{2+} 10 \mu$ moles; $\triangle-\triangle$, melanoidin $+\mathrm{Cu}^{2+} 30 \mu$ moles. 


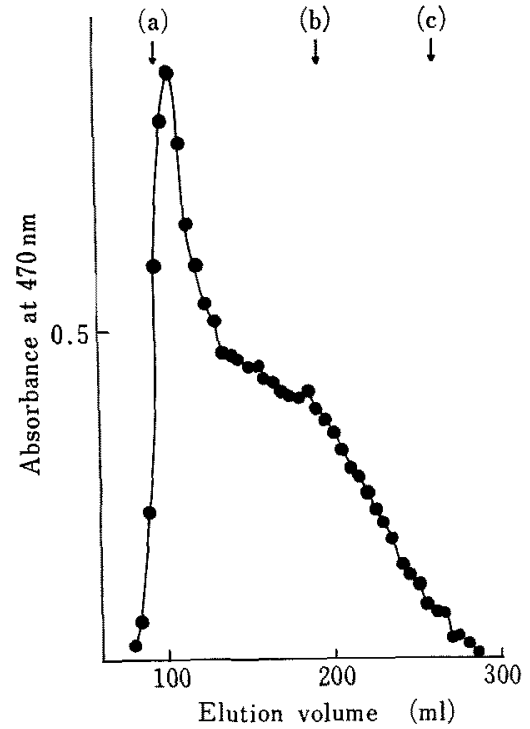

FIG. 12. Gel Permeation Chromatography of Melanoidin on Bio-Gel P-300.

Column, $3 \times 85 \mathrm{~cm}$, was filled with glass beads $(\phi=7 \sim$ $9 \mathrm{~mm}$ ) in order to facilitate elution procedure. Net volume of gel was $220 \mathrm{ml}$. Developing solvent was $0.1 \mathrm{M}$ acetate buffer ( $\mathrm{pH} 6.0$ ). (a) blue dextran $\left(2 \times 10^{5}\right)$, (b) ovalbumin $\left(4.5 \times 10^{4}\right)$, (c) flavin mononucleotide $\left(5 \times 10^{2}\right)$.

as seen in Fig. 12.

Estimation of the interaction between melanoidin and metallic ion by dialysis equilibrium

Dialysis equilibrium was carried out at low concentration of metallic ions where no coagulation occurred. The binding of metals with melanoidin was confirmed as seen in Table I, indicating significant decreases of free metallic ions in the medium during dialysis.

Now, the following equation was assumed in an attempt to estimate the affinity of melanoidin with ferric or cupric ion.

$$
\text { Mel }+n \text { Met } \underset{K}{\rightleftharpoons} \operatorname{Mel}(\text { Met })_{n}
$$

where Mel is melanoidin molecule, Met is metallic ion and $K$ is the stability constant. From this, the following relation is derived.

$$
K=\frac{\left([\mathrm{Met}]_{0}-[\mathrm{Met}]\right) / n}{\left\{[\mathrm{Mel}]-\left([\mathrm{Met}]_{0}-[\mathrm{Met}]\right) / n\right\}[\mathrm{Met}]^{n}}
$$

where [Met] $]_{0}$ and [Met] are the initial and the final concentration of metallic ions, and [Mel] is the concentration of melanoidin. If [Met] is $[\mathrm{Met}]_{\mathrm{I}}$ when $[\mathrm{Mel}]$ is $[\mathrm{Mel}]_{1}$, and if [Met] is $[\mathrm{Met}]_{2}$ when $[\mathrm{Mel}]$ is $[\mathrm{Mel}]_{2}$, the following equation is derived from the above relation by eliminating $K$.

$$
\begin{aligned}
& n \log [\mathrm{Met}]_{2} /[\mathrm{Met}]_{1}=\log \frac{[\mathrm{Mel}]_{1}\left([\mathrm{Met}]_{0}-[\mathrm{Met}]_{2}\right)}{[\mathrm{Mel}]_{2}\left([\mathrm{Met}]_{0}-[\mathrm{Met}]_{1}\right)} \\
& +\log \{1 \\
& \left.+\frac{[\mathrm{Met}]_{0}-[\mathrm{Met}]_{2}-[\mathrm{Mel}]_{2} /[\mathrm{Mel}]_{1}\left([\mathrm{Met}]_{0}-[\mathrm{Met}]_{1}\right)}{n[\mathrm{Mel}]_{2}-\left([\mathrm{Met}]_{0}-[\mathrm{Met}]_{2}\right)}\right\}
\end{aligned}
$$

If the molecular weight of melanoidin is assumed to be $10^{5}$ as above mentioned, $n$ can be determined from (3) using the data presented in Table I. Moreover, (2) gives the value of $\log K$ when $n$ is given. The results are shown in Table II.

Table I. Concentration of Metallic Ions after Dialysis EQULIBrium

\begin{tabular}{ccc}
\hline Melanoidin $^{a 1}$ & $25 \mathrm{mg}$ & $125 \mathrm{mg}$ \\
\hline $\mathrm{Fe}^{3+b\}}$ & $5.04 \times 10^{-5} \mathrm{M}$ & $3.22 \times 10^{-5} \mathrm{M}$ \\
$\mathrm{Cu}^{2+c)}$ & $6.49 \times 10^{-5} \mathrm{M}$ & $2.38 \times 10^{-5} \mathrm{M}$ \\
\hline
\end{tabular}

a) A certain amount of melanoidin dissolved in $50 \mathrm{ml}$ of $10^{-4} \mathrm{M} \mathrm{FeCl}_{3}$ in $0.1 \mathrm{M} \mathrm{KCl}$ solution was dialyzed against $200 \mathrm{ml}$ of the same solution in the manner as mentioned in EXPERIMENTAL.

$b$, of The concentration of metallic ion in the outer solution after equilibrium was attained.

Table II. Stability Constants of MetalMelanotdin CoMpleX and the Number of Binding Site ${ }^{a}$

\begin{tabular}{rrr} 
& $\log K$ & $n$ \\
\hline $\mathrm{Fe}^{3+}$ & 44.8 & 10 \\
$\mathrm{Cu}^{2+}$ & 32.3 & 7 \\
\hline
\end{tabular}

a) The calculation method is shown in the description.

Effect of oxidation of melanoidin on coagulation by metallic ions

Thirty $\mathrm{ml}$ of $0.03 \%$ aqueous solution of melanoidin to which $10 \mathrm{ml}$ of $n$-butanol was added was titrated with 2,6-dichlorophenolindophenol in $n$-butanol until the color of the 
oxidant did not fade out in vigorous shaking. After centrifuged, an aliquot of the lower aqueous layer containing oxidized melanoidin was subjected to coagulating treatment with metallic ions including $\mathrm{Fe}^{3+}, \mathrm{Al}^{3+}$ and $\mathrm{Cu}^{2+}$ at $10^{-3} \mathrm{M}$ at $\mathrm{pH}$ 3.8. However, no difference in coagulation between oxidized and nonoxidized melanoidin was recognized irrespectively of the kind of metals. Therefore, reductone groups such as enaminol appear to play little role in binding metallic ions in this experiment.

\section{DISCUSSION}

The total amount of protons released during titration from $\mathrm{pH} 2.5$, proposed as isoelectric point, to $\mathrm{pH} 11.0$ was estimated $c a .500$ per $10^{5} \mathrm{~g}$ of melanoidin, which is in rough approximation assumed for the molecular weight of melanoidin as mentioned above. On the other hand, based on the elementary composition of melanoidin as presented in EXPERIMENTAL, the number of each element per one molecule of melanoidin is calculated as follows; $\mathrm{C}: 4420, \mathrm{H}: 5100, \mathrm{O}: 2230, \mathrm{~N}: 450$, respectively. Then, it should be noted that the number of proton released from melanoidin corresponds to that of nitrogen approximately in equimolar relation. This fact supports the assumption that the acidic (proton releasing) groups are originated mainly from amino acid residues contributing to nitrogen content in melanoidin molecule. Those possible groups are reasonably attributable to carboxyl group according to the $\mathrm{pH}$ value $(\mathrm{pH}$ $3 \sim 4$ ) at the inflection in the titration curve of melanoidin. Reducing groups such as enaminol, which is able to donate proton, are less than two moles (mole equivalent to ascorbic acid) per one molecule of melanoidin. So, reducing groups are less contributive to acidity of melanoidin, and not important for the estimation of metal-binding sites. This is also supported by the results obtained above, which show no influence of oxidation on coagulating melanoidin by metallic ions. If the carboxyl group relates to amino acid residue in melanoidin molecule as above proposed, it is probable that $\alpha$-carboxyl group in amino acid is involved in the polymeric structure without transformation. Further investigation, however, is necessary to identify the metal-binding site in relation to the structure of melanoidin.

It is worthy of notice that the stability constants $\left(\log K\right.$ ) of melanoidin for $\mathrm{Fe}^{3+}$ and $\mathrm{Cu}^{2+}$ are remarkably higher as compared with other chelating agents. For example, $\log K$ of EDTA for $\mathrm{Fe}^{3+}$ and $\mathrm{Cu}^{2+}$ at $\mathrm{pH} 3.8$ are 15 and 10 , respectively. The difference in $\log K$ of melanoidin from EDTA may be ascribed to multiplicity of metal-binding sites. The number of metals binding to melanoidin, which is expressed as $n$, seems to be smaller as compared with the number of protons released (ca. 250 per one molecule of melanoidin) during titration between $\mathrm{pH} 2.5$ and $\mathrm{pH} 3.8$. As complex formation proceeds to some extent, no more dissociative groups in melanoidin molecule may interact with metallic ions. It is reasonably considered that binding of metal causes masking of dissociative groups through folding molecular chain of melanoidin.

The above results have made it clear that melanoidin is considerably powerful in trapping catalyzing metals such as $\mathrm{Fe}^{3+}$ and $\mathrm{Cu}^{2+}$. This metal-binding ability should be considered to contribute to the antioxidative property of melanoidin.

\section{REFERENCES}

1) T. Gomyo, H. Kato, K. Udaka, M. Horikoshi and M. Fujimaki, Agr. Biol. Chem., 36, 125 (1972).

2) H. Kato, Shokuhin Eisei Gakkaishi, 14, 343 (1973).

3) S. Kuwabara, U. Shimizu and M. Yajima, Nippon Nôgeikagaku Kaishi, 46, 89 (1972).

4) N. Kato and I. Shibasaki, J. Ferment. Technol., 52, 177 (1974).

5) H. Maekawa and S. Aikawa, KASEAA, 12, 363 (1974).

6) H. L. Ong and R. E. Bisque, Soil Sci., 106, 220 (1968).

7) H. Irving and R. J. P. Williams, J. Chem. Soc., 1953, 3192; idem, Nature, 162, 746 (1948). 